\title{
Resistance in Winter Wheat Lines to Initial Infection and Spread Within Spikes by Deoxynivalenol and Nivalenol Chemotypes of Fusarium graminearum
}

Peter Horevaj, Department of Plant Pathology, University of Arkansas, Fayetteville 72701; Liane R. Gale, Department of Plant Pathology, University of Minnesota, St. Paul 55108; and Eugene A. Milus, Department of Plant Pathology, University of Arkansas

\begin{abstract}
Horevaj, P., Gale, L. R., and Milus, E. A. 2011. Resistance in winter wheat lines to initial infection and spread within spikes by deoxynivalenol and nivalenol chemotypes of Fusarium graminearum. Plant Dis. 95:31-37.

Head blight of wheat in the United States is caused primarily by the deoxynivalenol (DON)-producing chemotype of Fusarium graminearum. However, the discovery of the nivalenol (NIV) chemotype of $F$. graminearum in Louisiana and Arkansas necessitates having resistance in wheat to both chemotypes. The objectives of this research were to quantify resistance of selected winter wheat lines to initial infection and pathogen spread within spikes, to determine whether wheat lines selected for resistance to the DON chemotype also have resistance to the NIV chemotype, and to improve the methods for quantifying resistance to initial infection. A susceptible check (Coker 9835) and 15 winter wheat lines, which are adapted to the southeastern United States

and possess diverse sources of head blight resistance, were evaluated for head blight resistance in a series of greenhouse and growthchamber experiments. Significant levels of resistance to both initial infection and spread within a spike were found among the lines, and lines with resistance to isolates of the DON chemotype had even higher levels of resistance to isolates of the NIV chemotype. Quantifying resistance to initial infection was improved by standardizing the inoculum and environmental conditions. Additional information related to resistance to spread within a spike was obtained by calculating the area under the disease progress curve from 7 to 21 days after inoculation.
\end{abstract}

Head blight, or scab, is an important disease of wheat wherever frequent rainfall occurs before, during, and after flowering. Although several Fusarium spp. can cause head blight, the principal head blight pathogen in the United States is Fusarium graminearum sensu lato Schwabe (teleomorph Gibberella zeae (Schwein.) Petch; 38). Resistant cultivars are believed to be an important component of any integrated management program for head blight (5). Schroeder and Christensen (35) first proposed two types of resistance to head blight in wheat: resistance to initial infection (now referred to as type I resistance) and resistance to spread of blight symptoms within a spike (now referred to as type II resistance). In 1995, Mesterházy (27) proposed five types of active resistance: resistance to initial infection (type I), resistance to spread of the pathogen within a spike (type II), resistance to kernel infection (type III), tolerance (i.e., the ability to produce marketable grain in the presence of head blight (type IV), and resistance to mycotoxin accumulation in grain (type V). Whereas type I and type II resistances have been widely accepted and appear frequently in the published literature $(6,31)$, the three remaining types of resistance (types III, IV, and V) are not well defined and often are used differently in the literature $(8,27,29)$.

Resistance to spread of the pathogen within a spike (type II) has been the most studied type of resistance in wheat, and the Chinese cv. Sumai 3 is the most commonly used source of this type of head blight resistance worldwide (15). Type II resistance is measured by

Corresponding author: E. A. Milus

E-mail: gmilus@uark.edu

This material is based upon work supported by the United States Department of Agriculture (USDA) under Agreement No. 59-0790-4-115. This is a cooperative project with the U.S. Wheat \& Barley Scab Initiative. Any opinions, findings, conclusions, or recommendations expressed in this publication are those of the authors and do not necessarily reflect the view of the USDA.

Accepted for publication 5 September 2010.

doi:10.1094/PDIS-03-10-0167

(C) 2011 The American Phytopathological Society inoculating a single floret near the middle of the spike and counting the spikelets blighted due to disease spread, typically from 8 to 21 days after inoculation (dai) (8). As Schroeder and Christensen (35) showed, the fungus spreads from spikelet to spikelet mainly in the rachis and, with type II resistance, this spread is reduced. The single-floret inoculation technique has been routinely used in both field and greenhouse experiments (3).

Resistance to spread of disease in a spike (type II) is easier to quantify than resistance to initial infection (type I). The singlefloret inoculation technique used to evaluate type II resistance is more reliable and accurate and less sensitive to environmental factors, and has been widely accepted as a standard greenhouse screening method $(3,4,8,16)$. This technique has been used to transfer type II resistance from Sumai 3 and other lines to spring wheat cultivars that have been grown commercially $(17,26)$. However, under heavy disease pressure, lines with type II resistance can have several infected florets within a spike, resulting from several primary infections rather than from disease spread within the spike (5). In such cases, adding more genes for type II resistance may not increase the cultivar's resistance, whereas introgressing genes for type I resistance into lines with type II resistance should increase resistance to head blight (5).

Resistance to initial infection is typically evaluated by uniformly spraying spikes with a macroconidial suspension $(31,35)$. This procedure allows establishment of infection without wounding the spike tissue and provides even coverage of the spike with inoculum. Under field conditions, type I resistance is commonly measured as disease incidence (percentage of spikes with symptoms). A more accurate measure of resistance to initial infection is the number of florets blighted within spikes before symptoms have time to spread, most commonly evaluated 7 dai $(8,16)$. The level of resistance is determined relative to the percentage of florets blighted on a susceptible control. Reproducibility of results among experiments designed to quantify resistance to initial infection has been problematic and, relative to the use of resistance to spread within a spike, little effort has been made to select resistance to initial infection in wheat $(5,14,16,34)$. Having an accurate and practical method for quantifying resistance to initial infection may facilitate the development of cultivars with this type of resistance. Furthermore, it may be possible to develop a method that allows quantifi- 
cation of resistance to both initial infection and spread within a spike from the same experiment, thereby increasing the efficiency of selection.

Infection of the wheat rachis by $F$. graminearum causes formation of thick layers of wall appositions (papillae) in vascular tissue that leads to collapse of phloem parenchyma and vascular dysfunction (24). If vascular dysfunction is severe, the distal portion of a spike beyond the infection may die prematurely without being infected. This phenomenon has been referred to as "blighting" of the top part of the spike (4), "apical wilting", "choking", "premature death", or "premature ripening" (8). In the current study, "premature apical death" will be used to describe this phenomenon.

Food- and feed-safety issues have been the driving force behind the worldwide effort to manage head blight. $F$. graminearum reduces grain quality through the production of mycotoxins, such as the trichothecenes deoxynivalenol (DON) and nivalenol (NIV), making grain unsafe for human and livestock consumption (20). Based on production of trichothecenes, $F$. graminearum can be divided into two chemotaxonomic groups $(23,25)$. The DON chemotype predominantly produces DON and the acetyl derivatives, 3-acetyl-DON (3-ADON) and 15-acetyl-DON (15-ADON). The NIV chemotype predominantly produces NIV and 4-acetylNIV (4-ANIV).

Surveys of wheat grain infected with $F$. graminearum suggested that DON chemotypes predominate in North and South America $(9,36)$, which has been confirmed in pathogen population analyses $(19,41)$. Because of known toxicity, the United States Food and Drug Administration established an advisory level for DON toxin at $1 \mathrm{mg} \mathrm{kg}^{-1}$ in wheat flour for human consumption (2). No advisory levels for NIV have been established because pathogen populations with the NIV chemotype were not known to exist in the United States. However, the recent discovery of NIV chemotypes of $F$. graminearum, particularly in Louisiana and also Arkansas (18), necessitates having resistance to both DON and NIV chemotypes in cultivars adapted to the Mid-South. Furthermore, NIV has been shown to be more toxic than DON to animals $(30,40)$. On the other hand, isolates of $F$. graminearum and $F$. culmorum with a DON chemotype may be more phytotoxic or aggressive than isolates with a NIV chemotype $(11,28,37)$. However, differences in phytotoxicity of DON and NIV and resistance to these mycotoxins are not expected to be factors in type I resistance (8), because DON is not essential for primary infection or initial colonization of the plant (33). Miedaner and Reinbrecht (28) inoculated 12 rye lines and 8 wheat cultivars in the field using spray inoculation with one DON chemotype isolate and one NIV chemotype isolate of $F$. culmorum, a common cause of head blight in Europe, at three locations. Based on disease severity, yield, and toxin content in grain, all tested wheat cultivars and rye lines were more resistant to the NIV chemotype than the DON chemotype of F. culmorum. How- ever, the head blight reactions of U.S. winter wheat lines to the NIV chemotype of $F$. graminearum have never been determined.

The objectives of this research were to quantify resistance of selected winter wheat lines to initial infection and to pathogen spread within spikes, determine whether wheat lines selected for resistance to head blight caused by the DON chemotype also have resistance to the NIV chemotype, and improve the methods for quantifying type I resistance and the combination of types I and II. Preliminary reports of this research have been published $(21,22)$.

\section{Materials and Methods}

Resistance to pathogen spread within spikes (type II resistance). The susceptible cv. Coker 9835 and 15 winter wheat lines with resistance to the DON chemotype and with adaptation to field conditions and similar flowering times in Arkansas were used in this study (Table 1). The 15 resistant lines were selected in 2006 from among the following: 36 lines in the 2006 Southern Uniform Winter Wheat Scab Nursery, 5 lines from Hungary provided by Á. Mesterházy, 2 lines from Romania provided by M. Ittu, 2 lines from Slovakia provided by M. Katonova, 6 lines from the Czech Republic provided by P. Horčička, and several breeding lines developed at the University of Arkansas. Of the 15 selected resistant lines, 8 contained one or more known sources of resistance gene Fhb1 (Ning7840, Nobeoka Bozu, and Sumai3), 5 contained one or more exotic, non-Fhbl sources of resistance (Catbird, Super Zlatno, and Sha3, Ning8026), and 6 contained a native source of resistance (Freedom, Ernie, Roane, and Bess). Of the eight lines with a source of $F h b 1$, five were determined to contain $F h b 1$ and one was heterogeneous for Fhb1 (unpublished data). Seed of each line were germinated on moist germination paper in petri dishes at room temperature, and five vigorous seedlings of each line were transplanted to a $7.5-\mathrm{cm}^{2}$ pot (five seedlings per pot) containing potting mix (six parts peat moss, four parts vermiculite, two parts perlite, three parts Roxana silt loam soil, and three parts sand). Plants were vernalized for 8 weeks in a growth chamber programmed at $6^{\circ} \mathrm{C}$ from 0800 to $2000 \mathrm{~h}$ and at $4^{\circ} \mathrm{C}$ from 2000 to $0800 \mathrm{~h}$ with a 12 -h photoperiod. During vernalization, plants were fertilized every 3 weeks with Peters 20-20-20 N-P-K (Spectrum Group Division of U.I.C., St. Louis) at the rate of $0.2 \mathrm{~g} \mathrm{liter}^{-1}$. After vernalization, plants were transplanted into $15-\mathrm{cm}$ pots and moved to a greenhouse at 16 to $22^{\circ} \mathrm{C}$ with a 16 -h photoperiod. Each pot was fertilized with $6 \mathrm{~g}$ of Osmocote 14-14-14 (N-P-K) slow-release fertilizer (The Scotts Company LLC, Marysville, $\mathrm{OH}$ ), and $34 \mathrm{mg}$ of Soluble Trace Element Mix (The Scotts Company LLC). To control aphids, thrips, and barley yellow dwarf, plants were treated with imidacloprid insecticide Marathon (OHP, Inc., Mainland, PA) at the rate of $5 \mathrm{mg}$ a.i. per pot after vernalization and at 3-week intervals until the end of the experiment.

Four isolates of $F$. graminearum that originated from 2003 wheat plots at the Louisiana State University AgCenter in Crowley were

Table 1. Wheat lines used in this study to evaluate resistance to initial infection and spread within spikes by deoxynivalenol and nivalenol chemotypes of Fusarium graminearum, their pedigrees, and their contributors

\begin{tabular}{|c|c|c|}
\hline Line & Pedigree & Contributor \\
\hline ARGE97-1042-4-5 & Mason/Catbird & Milus \\
\hline ARGE97-1033-10-2 & Freedom/Catbird & Milus \\
\hline ARGE97-1064-13-5 & Mason//Freedom/Super Zlatno & Milus \\
\hline ARGE97-1047-4-2 & Pio2684/3 Ning 7840//Parula/Veery \# 6 & Milus \\
\hline ARGE97-1048-3-6 & Mason//Sha 3/Catbird & Milus \\
\hline AR97002-2-1 & AR396-4-2/Ning 8026 & Bacon \\
\hline VA04W-433 & Ning 7840/Pio2684//96-54-244 (CK9803/Freedom) & Griffey \\
\hline VA04W-628 & Ernie//Ning7840/Ernie & Griffey \\
\hline Roane & VA71-54-147 (CI17449)/Coker68-15//IN65309C1-18-2-3-2 & Griffey \\
\hline Bess & MO11769/Madison & McKendry \\
\hline NC03-11465 & Ning 7840/P2643//NC95-22426 & Murphy \\
\hline SZ 13 & Ringo Star/Nobeoka Bozu & Mesterházy \\
\hline SZ 14 & Ringo Star/Nobeoka Bozu & Mesterházy \\
\hline $\mathrm{Fg} 365$ & Ságvári/Nobeoka Bozu/Mini Mano/Sum3 & Mesterházy \\
\hline Fg 368 & Zugoly/Reka/Nobeoka Bozu & Mesterházy \\
\hline Coker 9835 & Susceptible check & $\ldots$ \\
\hline
\end{tabular}


used for inoculations. Isolates were chosen based on trichothecene type determination using multiplex polymerase chain reaction (PCR) primers (39), genotyping with PCR-restriction fragment length polymorphisms, and determination of levels of toxin production and aggressiveness in greenhouse experiments in Minnesota that took place during winter months (18). Isolates 03-29 and 03-112 were selected from among 8 NIV chemotype isolates to represent NIV chemotypes with low and high levels of NIV production, respectively, and isolates 03-57 and 03-113 (both with a 3ADON trichothecene type) were selected from among 11 DON chemotype isolates to represent DON chemotypes with low and high levels of DON production, respectively (18). Isolates were stored on desiccated filter paper at $4^{\circ} \mathrm{C}$ as described by Correll et al. (10), and fresh cultures for each experiment were started from isolates in storage. Macroconidia of each isolate were produced in mung bean broth as described by Desjardins et al. (13). Briefly, $250 \mathrm{ml}$ of inoculated mung bean broth was shaken in 500-ml flasks at room temperature for 4 days at $140 \mathrm{rpm}$. On the day of inoculation, the concentration of macroconidia was determined with a hemacytometer and adjusted to $5 \times 10^{4}$ spores $\mathrm{ml}^{-1}$.

Plants were inoculated when a group of four pots for a given line had spikes at the flowering stage. Within each pot, only spikes with anthers protruding from three to five primary florets (each spikelet usually has two primary florets that are the largest and first to flower; 1) on the day of inoculation were selected, and the other spikes were removed. A single primary floret near the center of each spike was injected with $20 \mu \mathrm{l}$ of inoculum using a PB600-1 repeating dispenser (Hamilton Co., Reno, NV). Three to eight spikes were inoculated per pot. Each inoculated floret was marked using a black nontoxic permanent pen (Sharpie, Sanford, IL). Plants were incubated on a mist bench at 16 to $22^{\circ} \mathrm{C}$ and misted for $20 \mathrm{~s}$ every $20 \mathrm{~min}$ to promote infection. After $72 \mathrm{~h}$ of misting, inoculated plants were moved to a greenhouse at 22 to $24^{\circ} \mathrm{C}$ with a 16-h photoperiod.

The total number of primary florets and the number of primary florets blighted per spike were counted 21 dai and the percentage of florets blighted was calculated. The upper portion of some spikes died prematurely without being infected because the pathogen infected the rachis, likely cutting off nutrients to the tip of the spike. Only primary florets blighted by the pathogen were counted, and each spike was rated for the presence $(=1)$ or absence $(=0)$ of premature apical death of the spike. Data were averaged across spikes within each pot, and this average represented the incidence (expressed as a percentage) of premature apical death across all the spikes in the pot.

The experimental design was a completely randomized design consisting of 16 wheat lines, two chemotypes (DON and NIV), two levels of toxin production (low and high) within each chemotype, and three replicates (pots). The experiment was conducted three times (runs). Lines, chemotypes, levels within chemotypes, and interactions among these factors were treated as fixed effects. Runs, replicates, and interactions with these factors were treated as random effects. Data were analyzed using Proc GLM in SAS (version 9.1.3; SAS Institute, Cary, NC). When fixed effects were significant $(P \leq 0.05)$, appropriate means were separated using Tukey's honestly significant difference (HSD) test at $P=0.05$. To determine whether wheat lines reacted similarly to DON and NIV chemotypes, the ranks of the wheat lines inoculated with DONchemotype isolates were correlated with the ranks of the wheat lines inoculated with NIV-chemotype isolates using the Spearman's correlation option in Proc Corr of SAS.

Resistance to initial infection (type I resistance). A procedure developed by Patton-Özkurt et al. (32) was modified for this study. The previously described wheat lines were used with the exception of line Fg 365, which did not vernalize sufficiently. In the fall of 2008, vigorous seedlings of each line were transplanted to plastic cones (410-cm ${ }^{3}$ D25L Deepots; Stuewe \& Sons, Inc., Corvallis, $\mathrm{OR})$. Each cone contained one seedling. Plants were vernalized for 8 weeks in a growth chamber programmed at $8^{\circ} \mathrm{C}$ from 0800 to $2000 \mathrm{~h}$ and $5^{\circ} \mathrm{C}$ from 2000 to $0800 \mathrm{~h}$, with a 12 -h photoperiod from 0800 to $2000 \mathrm{~h}$. After vernalization, plants were moved to a greenhouse at 17 to $22^{\circ} \mathrm{C}$ with a 14-h photoperiod, and each cone was fertilized with $1.5 \mathrm{~g}$ of Osmocote 14-14-14 (N-P-K) slowrelease fertilizer and $10 \mathrm{mg}$ of Soluble Trace Element Mix. Plants were treated approximately every 21 days with imidacloprid insecticide (Marathon, 1.25-mg a.i. per cone) to control aphids, thrips, and barley yellow dwarf (caused by the aphid-transmitted Barley yellow dwarf virus).

Macroconidia of isolates 03-112 (high NIV producer) and 03113 (high DON producer) were produced in mung bean broth as described by Desjardins et al. (13), except that four 500-ml flasks of inoculum were produced for each isolate. The method of Mesterházy (27) was used to evaluate aggressiveness of inoculum in each flask. Briefly, 10 surface-disinfested wheat seeds were placed on blotter paper in a petri dish, inoculated with a series of inoculum dilutions ( $4 \mathrm{ml} / \mathrm{dish}$ ), and the number of diseased seedlings in each of two replicate petri dishes was counted 6 to 7 days later. The batch (flask) of inoculum that caused the highest incidence of pre- or post-germination damping off at the highest dilution was selected, adjusted to $1 \times 10^{5}$ spores $\mathrm{ml}^{-1}$ using a hemacytometer, and stored in $10-\mathrm{ml}$ aliquots at $-18^{\circ} \mathrm{C}$ until the day of inoculation, as described by Dill-Macky (14). Previous work has shown that freezing does not reduce macroconidial germination rates (7). The same batch of inoculum of each isolate was used for an entire experiment (run).

Pairs of plants were inoculated at flowering stage when anthers were visible on 10 to 20 primary florets per spike. One plant of each pair was inoculated with isolate 03-112 and the other with isolate 03-113. Each spike was physically isolated and uniformly sprayed with approximately $0.6 \mathrm{ml}$ of inoculum using an atomizer commonly used for rust inoculation (G-R Manufacturing Co., Manhattan, KS). To make inoculations on various days more uniform, inoculations were always begun at approximately $1400 \mathrm{~h}$. To promote infection and disease development, individual spikes were enclosed in plastic bags immediately after inoculation, and plants were incubated in a growth chamber at $23^{\circ} \mathrm{C}$ with a 14 -h photoperiod. Bags were removed after $48 \mathrm{~h}$ and, after 7 days, plants were moved to a greenhouse at 22 to $24^{\circ} \mathrm{C}$ with a 16-h photoperiod. At 4 , $5,6,7,14$, and 21 dai, the number of primary florets blighted on each spike was counted and the percentage of florets blighted based on the total number of primary florets per spike was calculated.

The experiment was conducted three times (runs). The experimental design for each run was a completely randomized design consisting of 15 wheat lines, one DON and one NIV chemotype isolate, and seven replicates (cones). Plants of each wheat line were always inoculated in pairs, whereby one plant in each pair was inoculated with the DON-chemotype isolate and the other plant was inoculated with the NIV-chemotype isolate. Line, chemotype, and the line-chemotype interaction were treated as fixed effects. Run, replicate, and interactions with these factors were treated as random effects. Data were analyzed using Proc GLM, SAS (version 9.1.3). Based on results of analysis of variance, appropriate means were separated using Tukey's HSD test at $P=0.05$. To determine how well area under the disease progress curve (AUDPC) across 7 to 21 days after spray inoculation was associated with resistance to spread within a spike, as determined using single-floret inoculation, correlation coefficients were calculated separately for DON and NIV chemotypes using the Pearson option in Proc Corr of SAS.

\section{Results}

Resistance to pathogen spread within spikes. The high toxinproducing isolate within each chemotype caused significantly more disease as measured by the percentage of florets blighted $(P=$ 0.019 ) than the low toxin-producing isolate (Table 2). Averaged across all lines and runs, the low and high NIV-producing isolates blighted 11.9 and $13.4 \%$ of florets, respectively, and the low and high DON-producing isolates blighted 17.1 and $18.3 \%$ of florets, respectively. Across all lines, spikes averaged 33 primary florets; therefore, one blighted floret equaled approximately $3 \%$ severity. 
Therefore, the 1.2 and $1.5 \%$ differences between isolates within a chemotype represent half or less of a blighted floret. Although statistically different, these differences do not appear to have biological significance. Therefore, data within each chemotype were pooled across both isolates in subsequent analyses.

The line-chemotype interaction was significant $(P=0.015)$, indicating that lines ranked differently for the different chemotypes (Table 2). For each line, however, the percentage of florets blighted by the NIV chemotype was consistently less than the percentage of florets blighted by the DON chemotype (Table 3), and only ARGE97-1048-3-6 had a significant difference between chemotypes $(P=0.05)$, indicating that the interactions were due only to the magnitude of the differences between DON and NIV chemotypes. In addition, there was a positive Spearman correlation $(\rho=$ $0.84, P<0.0001$ ) between the rank of wheat lines for percentage of florets blighted by the DON and NIV chemotypes. For both chemotypes, all resistant lines had a significantly lower percentage of florets blighted than the susceptible check (Table 3 ).

The run-line interaction was significant $(P<0.001)$ for the percentage of florets blighted (Table 2), indicating that the lines ranked differently among runs (environments). The variation due to this interaction accounted for $27 \%$ of the total variance (data not shown), indicating that several repetitions (runs) of the experiment should be conducted to deal with this form of genotypeenvironment interaction.

The DON chemotype caused a significantly higher incidence of premature apical death than the NIV chemotype $(P=0.026$; Table
2). Within each chemotype, the low and high toxin-producing isolates caused similar levels of premature apical death $(P=0.309)$. The line-chemotype interaction was significant $(P=0.009)$, indicating that lines ranked differently for the chemotypes. For each line, however, incidence of premature apical death caused by the NIV chemotype was always less than that caused by the DON chemotype (Table 3), indicating that the interaction was caused only by differences in magnitude. Within each chemotype, the susceptible check (Coker 9835) had a significantly higher incidence of premature apical death than any of the resistant lines. The run-line and run-chemotype-line interactions were significant $(P$ $=0.034$ and 0.007 , respectively; Table 2). However, these components of variance accounted for only 9.8 and $10.8 \%$, respectively, of the total variance (data not shown), indicating that these interactions accounted for small portions of the total variance.

Resistance to initial infection. The first visual symptoms of infection were observed at 4 dai but these were not distinct enough to count accurately. On all lines, the percentage of florets blighted increased daily between 4 and 7 dai, and there was no clear distinction between florets blighted from initial infection or subsequent spread. Symptoms on individual florets were distinct at 5 and 6 dai, but the spread of symptoms was noticeable at 7 dai. The linechemotype interaction was not significant at 4 and 5 dai $(P=$ 0.1950 and 0.1034 , respectively; Table 4$)$ but was significant at 6 and 7 dai $(P=0.0447$ and 0.0002 , respectively). The significant interactions at 6 and 7 dai were due to the DON chemotype causing more disease than the NIV chemotype on Coker 9835 and

Table 2. Statistical tests for the main effects and interactions of run, line, chemotype, and level within chemotype on percentage of florets blighted and incidence of premature apical death 21 days after inoculation of 16 wheat lines inoculated with two deoxynivalenol (DON) and two nivalenol (NIV) chemotype isolates of Fusarium graminearum using the single-floret inoculation method to evaluate resistance to spread within spikes

\begin{tabular}{|c|c|c|c|c|c|}
\hline \multirow[b]{2}{*}{ Effects and interactions } & \multirow[b]{2}{*}{ df } & \multicolumn{2}{|c|}{ Florets blighted (\%) } & \multicolumn{2}{|c|}{ Premature apical death } \\
\hline & & $F$ value & $P$ value & $F$ value & $P$ value \\
\hline Run $^{\mathrm{z}}$ & 2 & 0.88 & 0.441 & 4.53 & 0.105 \\
\hline Line & 15 & 12.05 & $<0.001$ & 10.10 & $<0.001$ \\
\hline Chemotype & 1 & 30.48 & 0.031 & 37.03 & 0.026 \\
\hline Level (chemotype) & 2 & 12.65 & 0.019 & 1.60 & 0.309 \\
\hline Line $\times$ chemotype & 15 & 2.53 & 0.015 & 2.74 & 0.009 \\
\hline Line $\times$ level (chemotype) & 30 & 1.07 & 0.402 & 1.14 & 0.325 \\
\hline Run $\times$ chemotype & 2 & 3.67 & 0.086 & 2.51 & 0.128 \\
\hline Run $\times$ line & 30 & 4.80 & $<0.001$ & 1.97 & 0.034 \\
\hline Run $\times$ level (chemotype) & 4 & 0.30 & 0.874 & 1.11 & 0.361 \\
\hline Run $\times$ chemotype $\times$ line & 30 & 1.59 & 0.063 & 2.12 & 0.007 \\
\hline Run $\times$ line $\times$ level $($ chemotype $)$ & 60 & 0.80 & 0.859 & 0.83 & 0.808 \\
\hline
\end{tabular}

${ }^{\mathrm{z}}$ Represents the repetition of the entire experiment.

Table 3. Resistance to spread within spikes (type II resistance) for 16 wheat lines as measured by the percentage of florets blighted and incidence of premature apical death 21 days after single-floret inoculation with two deoxynivalenol (DON) and two nivalenol (NIV) chemotype isolates of Fusarium graminearum $^{\mathrm{z}}$

\begin{tabular}{|c|c|c|c|c|}
\hline \multirow[b]{2}{*}{ Line } & \multicolumn{2}{|c|}{ Percentage of florets blighted } & \multicolumn{2}{|c|}{ Incidence of premature apical death } \\
\hline & DON chemotype & NIV chemotype & DON chemotype & NIV chemotype \\
\hline VA04W-433 & $6.9 \mathrm{a}$ & $6.3 \mathrm{a}$ & $8.9 \mathrm{a}-\mathrm{c}$ & $0.9 \mathrm{a}$ \\
\hline ARGE97-1033-10-2 & $7.6 \mathrm{a}$ & $5.9 \mathrm{a}$ & $1.1 \mathrm{a}$ & $0.0 \mathrm{a}$ \\
\hline Fg 368 & $8.4 \mathrm{a}$ & $5.6 \mathrm{a}$ & $6.1 \mathrm{a}-\mathrm{c}$ & $1.4 \mathrm{a}$ \\
\hline Bess & $9.8 \mathrm{a}$ & $8.4 \mathrm{a}$ & $7.3 \mathrm{a}-\mathrm{c}$ & $1.1 \mathrm{a}$ \\
\hline Roane & $11.3 \mathrm{ab}$ & $7.6 \mathrm{a}$ & $22.7 \mathrm{a}-\mathrm{d}$ & $9.1 \mathrm{a}-\mathrm{c}$ \\
\hline VA04W-628 & $12.1 \mathrm{ab}$ & $10.4 \mathrm{a}$ & $21.5 \mathrm{a}-\mathrm{d}$ & $6.4 \mathrm{a}-\mathrm{c}$ \\
\hline AR97002-2-1 & $12.9 \mathrm{a}-\mathrm{c}$ & $9.7 \mathrm{a}$ & $23.8 \mathrm{a}-\mathrm{d}$ & $0.0 \mathrm{a}$ \\
\hline Fg 365 & $14.6 \mathrm{a}-\mathrm{e}$ & $14.1 \mathrm{a}-\mathrm{e}$ & $13.5 \mathrm{a}-\mathrm{c}$ & $5.5 \mathrm{a}-\mathrm{c}$ \\
\hline SZ 14 & $15.0 \mathrm{a}-\mathrm{f}$ & $9.3 \mathrm{a}$ & $32.9 \mathrm{~b}-\mathrm{d}$ & $0.0 \mathrm{a}$ \\
\hline SZ 13 & $15.7 \mathrm{a}-\mathrm{f}$ & $6.0 \mathrm{a}$ & $21.5 \mathrm{a}-\mathrm{d}$ & $0.0 \mathrm{a}$ \\
\hline NC03-11465 & $23.0 \mathrm{c}-\mathrm{f}$ & $13.6 \mathrm{a}-\mathrm{d}$ & $7.2 \mathrm{a}-\mathrm{c}$ & $2.2 \mathrm{a}$ \\
\hline ARGE97-1042-4-5 & $23.8 \mathrm{~d}-\mathrm{f}$ & $21.2 \mathrm{~b}-\mathrm{f}$ & $29.4 \mathrm{a}-\mathrm{d}$ & $4.7 \mathrm{ab}$ \\
\hline ARGE97-1047-4-2 & $24.0 \mathrm{~d}-\mathrm{f}$ & $15.7 \mathrm{a}-\mathrm{f}$ & $35.9 \mathrm{~cd}$ & $10.8 \mathrm{a}-\mathrm{c}$ \\
\hline ARGE97-1064-13-5 & $24.3 \mathrm{ef}$ & $14.9 \mathrm{a}-\mathrm{f}$ & $51.1 \mathrm{~d}$ & $14.4 \mathrm{a}-\mathrm{c}$ \\
\hline ARGE97-1048-3-6 & $25.4 \mathrm{f}$ & $11.5 \mathrm{ab}$ & $29.8 \mathrm{a}-\mathrm{d}$ & $5.6 \mathrm{a}-\mathrm{c}$ \\
\hline Coker 9835 & $48.5 \mathrm{~g}$ & $42.8 \mathrm{~g}$ & $88.7 \mathrm{e}$ & $49.2 \mathrm{~d}$ \\
\hline
\end{tabular}

${ }^{\mathrm{z}}$ Lines are ranked by values of percentage of florets blighted for the DON chemotype. Values within a variable followed by the same letter are not significantly different by Tukey's honestly significant difference test at $P=0.05$. 
NC03-11465, lines that had the most spread within spikes as measured by AUDPC between 7 and 21 dai. Therefore, the spread of symptoms appeared to begin at 6 dai, and data recorded at 5 dai were selected as the most accurate estimate of resistance to initial infection. The line-chemotype interaction was not significant $(P=0.103)$, indicating that lines ranked similarly for both DON and NIV chemotypes at 5 dai (Table 4). Furthermore, the DON and NIV chemotypes caused similar levels of disease $(P=0.162)$. The DON chemotype averaged $6.9 \%$ florets blighted and the NIV chemotype averaged $3.7 \%$ florets blighted. All resistant lines had significantly lower percentages of florets blighted at 5 dai than the susceptible check, indicating they all had some level of type I resistance (Table 5).

The line-chemotype interaction was significant $(P<0.001)$ for AUDPC across 7 to 21 dai (Table 4). For all lines, AUDPC for the DON chemotype was numerically higher than the AUDPC for the NIV chemotype (Table 5). The difference was significant for six lines, indicating that, for these lines, the DON chemotype caused more disease and spread more aggressively than the NIV chemotype. All resistant lines had significantly lower AUDPC values than the susceptible check $(P=0.05)$, indicating that all lines had type I or type II resistance. Furthermore, there were positive Pearson's correlations for DON $(r=0.77, P<0.0001)$ and NIV $(r=0.84, P<$ $0.0001)$ chemotypes between AUDPC and percentage of florets blighted 21 days after single-floret inoculation to quantify levels of resistance to spread within a spike, suggesting that AUDPC was associated with type II resistance.

The run-chemotype interaction was significant $(P<0.001)$ for both percentage of florets blighted at 5 dai and AUDPC across 7 to 21 dai (Table 4). However, values for the NIV chemotype were always less than the values for the DON chemotype (data not shown), indicating that the interactions were due only to the magnitude of the differences between DON and NIV chemotypes. The run-line interaction was significant $(P=0.005)$ for the AUDPC across 7 to 21 dai (Table 4). However, this component of variance accounted for only $7.3 \%$ of the total variance, indicating that this interaction accounted only for a small portion of the total variance.

\section{Discussion}

The results of this study indicate that wheat lines with resistance to isolates of the DON chemotype of $F$. graminearum were even more resistant to isolates of the NIV chemotype. Although these results were obtained using only two DON and two NIV chemotype isolates from one location in Louisiana, the results likely pertain to a broader range of DON and NIV chemotype isolates because there is little evidence for differential line-isolate interactions in the wheat $-F$. graminearum pathosystem $(3,4,27)$. Furthermore, the results were consistent across wheat lines with $F h b 1$, four sources of exotic non-Fhbl resistance, and four sources of native resistance. Both chemotypes caused similar levels of initial infection measured at 4 and 5 dai (before blighting symptoms began to spread), indicating that both chemotypes had similar abilities to initiate infections across the diverse resistance sources used in this study. These results support the conclusion of Proctor et al. (33), who reported that DON does not play a crucial role in the initial infection of wheat florets.
In all evaluations of spread of blighting symptoms in this study, the DON chemotype caused more disease than the NIV chemotype. Differences between the DON and NIV chemotype were most pronounced for the percentage of spikes with premature apical death. Averaged across all wheat lines and both isolates within a chemotype, isolates of the DON and NIV chemotype caused premature apical death on 25.1 and $7.0 \%$ of spikes, respectively. These results support the conclusions of previous research $(11,12,28,37)$ that DON chemotypes of $F$. graminearum are more aggressive than NIV chemotypes. Selecting lines for resistance to the DON chemotype should also select for resistance to the NIV chemotype. The ability of resistance genes to reduce disease caused by both chemotypes is important in Arkansas and Louisiana because both chemotypes are important causes of wheat head blight in this region (18).

Florets at the tip of spikes that were affected by premature apical death rather than direct fungal infection were not included in the count of florets blighted by the pathogen. Although this likely reduced the percentage of florets blighted on these spikes, lines with premature apical death were still identified as lines with the low resistance to spread, indicating that lines with low resistance to spread within a spike are more susceptible to rachis colonization and premature apical death. This is in agreement with the observations of Bai and Shaner (4), who reported that premature apical death was common among susceptible cultivars in greenhouse and field tests.

Providing a uniform post-inoculation environment for all inoculated plants is important for experiments such as those in this

Table 5. Percentage of florets blighted (FB) 5 days after inoculation (dai) and area under the disease progress curve (AUDPC) across 7 to 21 dai for 15 winter wheat lines inoculated using a spray inoculation technique with one deoxynivalenol (DON) and one nivalenol (NIV) chemotype isolate of Fusarium graminearum to evaluate resistance to initial infection and subsequent spread within spikes ${ }^{y}$

\begin{tabular}{lccc}
\hline & & \multicolumn{2}{c}{ AUDPC across 7 to 21 dai } \\
\cline { 3 - 4 } Line & FB $(\boldsymbol{\%})^{\mathbf{z}}$ & $\begin{array}{c}\text { DON } \\
\text { chemotype }\end{array}$ & $\begin{array}{c}\text { NIV } \\
\text { chemotype }\end{array}$ \\
\hline SZ 14 & $1.6 \mathrm{a}$ & $85 \mathrm{a}-\mathrm{c}$ & $58 \mathrm{ab}$ \\
Bess & $1.6 \mathrm{a}$ & $72 \mathrm{a}-\mathrm{c}$ & $33 \mathrm{a}$ \\
ARGE97-1042-4-5 & $1.9 \mathrm{ab}$ & $78 \mathrm{a}-\mathrm{c}$ & $35 \mathrm{a}$ \\
SZ 13 & $2.3 \mathrm{a}-\mathrm{c}$ & $95 \mathrm{a}-\mathrm{c}$ & $48 \mathrm{a}$ \\
AR97002-2-1 & $2.4 \mathrm{a}-\mathrm{c}$ & $81 \mathrm{a}-\mathrm{c}$ & $55 \mathrm{a}$ \\
ARGE97-1033-10-2 & $3.6 \mathrm{a}-\mathrm{d}$ & $120 \mathrm{a}-\mathrm{d}$ & $76 \mathrm{a}-\mathrm{c}$ \\
VA04W-628 & $4.5 \mathrm{a}-\mathrm{d}$ & $208 \mathrm{c}-\mathrm{f}$ & $43 \mathrm{a}$ \\
NC03-11465 & $5.5 \mathrm{a}-\mathrm{d}$ & $485 \mathrm{~h}$ & $201 \mathrm{~b}-\mathrm{f}$ \\
ARGE97-1064-13-5 & $5.6 \mathrm{a}-\mathrm{d}$ & $266 \mathrm{e}-\mathrm{g}$ & $113 \mathrm{a}-\mathrm{d}$ \\
VA04W-433 & $6.0 \mathrm{a}-\mathrm{d}$ & $246 \mathrm{~d}-\mathrm{g}$ & $151 \mathrm{a}-\mathrm{f}$ \\
Roane & $6.1 \mathrm{a}-\mathrm{d}$ & $282 \mathrm{fg}$ & $97 \mathrm{a}-\mathrm{c}$ \\
ARGE97-1048-3-6 & $6.4 \mathrm{~b}-\mathrm{d}$ & $211 \mathrm{c}-\mathrm{f}$ & $115 \mathrm{a}-\mathrm{d}$ \\
ARGE97-1047-4-2 & $6.8 \mathrm{~cd}$ & $369 \mathrm{gh}$ & $149 \mathrm{a}-\mathrm{f}$ \\
Fg 368 & $7.5 \mathrm{~d}$ & $273 \mathrm{e}-\mathrm{g}$ & $131 \mathrm{a}-\mathrm{e}$ \\
Coker 9835 & $17.7 \mathrm{e}$ & $972 \mathrm{j}$ & $651 \mathrm{i}$ \\
\hline
\end{tabular}

${ }^{y}$ Means within FB or AUDPC followed by the same letter are not significantly different by Tukey's honestly significant difference test at $P=0.05$.

${ }^{z}$ Percent FB across DON and NIV chemotypes 5 dai.

Table 4. Statistical tests for the main effects and interactions of run, line, and chemotype on percentage of florets blighted 5 days after inoculation (dai) and area under the disease progress curve (AUDPC) across 7 to 21 dai of 15 wheat lines using a spray inoculation technique with one deoxynivalenol (DON) and one nivalenol (NIV) chemotype isolate of Fusarium graminearum to evaluate resistance to initial infection and spread within a spike

\begin{tabular}{|c|c|c|c|c|c|}
\hline \multirow[b]{2}{*}{ Effects and interactions } & \multirow[b]{2}{*}{ df } & \multicolumn{2}{|c|}{ Florets blighted (\%) } & \multicolumn{2}{|c|}{ AUDPC across 7 to 21 dai } \\
\hline & & $F$ value & $P$ value & $F$ value & $P$ value \\
\hline $\operatorname{Run}^{2}$ & 2 & 0.35 & 0.742 & 1.73 & 0.332 \\
\hline Line & 14 & 19.42 & $<0.001$ & 44.77 & $<0.001$ \\
\hline Chemotype & 1 & 4.73 & 0.162 & 16.97 & 0.054 \\
\hline Line $\times$ chemotype & 14 & 1.74 & 0.103 & 7.58 & $<0.001$ \\
\hline Run $\times$ chemotype & 2 & 14.57 & $<0.001$ & 11.67 & $<0.001$ \\
\hline Run $\times$ line & 28 & 1.50 & 0.146 & 2.71 & 0.005 \\
\hline Run $\times$ chemotype $\times$ line & 28 & 0.71 & 0.867 & 0.61 & 0.943 \\
\hline
\end{tabular}

${ }^{\mathrm{z}}$ Represents the repetition of the entire experiment. 
study, in which plants are inoculated at a certain growth stage across numerous days. This was especially important for experiments evaluating resistance to initial infection because data were recorded 5 dai, leaving little time for "averaging" of environmental effects that are more likely to occur in experiments that are conducted for longer time periods (e.g., 21 dai in a greenhouse). Compared with an earlier procedure for evaluating resistance to initial infection (32), inoculating at the same time of day, bagging spikes after inoculation rather than incubating plants under a mist system, and incubating inoculated plants in a growth chamber at a constant favorable temperature for disease development rather than on a greenhouse bench are likely to reduce environmental effects and improve the ability to detect smaller differences in levels of initial infection among the lines. Under the conditions in this study for evaluating resistance to initial infection, 5 dai was shown to be the optimal time for recording data without counting florets that were blighted by spread of symptoms rather than initial infection, and this likely contributed to the ability to detect small differences in initial infection.

As noted in previous reports $(5,14,34)$, increasing the levels of both resistance to initial infection and resistance to spread within a spike has been proposed as a means to increase head blight resistance of wheat cultivars in the field. The ability to quantify both types of resistance in one experiment as described in this study greatly improves the efficiency of obtaining these data and makes it more feasible to develop cultivars with high levels of both components of resistance.

The results of this study also indicate that significant levels of resistance to both initial infection (type I) and spread within a spike (type II) have been incorporated into several wheat lines adapted to the southeastern United States. Averaged across DON and NIV chemotype isolates, the number of initial infections for the 15 resistant lines was reduced by 58 to $91 \%$ compared with the number on the susceptible check, Coker 9835. Likewise, the number of blighted florets within a spike following single-floret inoculation for the 15 resistant lines was reduced by 48 to $86 \%$ and 50 to $87 \%$ compared with the number of blighted florets on Coker 9835 for the DON and NIV chemotype isolates, respectively. Reductions of this magnitude likely would have significant effects on head blight severity and mycotoxin accumulation in grain during natural head blight epidemics in commercial fields.

\section{Acknowledgments}

We thank P. Rohman and J. Hedge for technical assistance, E. Gbur, Jr. for statistical advice, and the people who contributed wheat lines for this study.

\section{Literature Cited}

1. Allan, R. E. 1980. Wheat. Pages 709-720 in: Hybridization of Crop Plants. R. W. Fehr and H. H. Hadley, eds. American Society of Agronomy and Crop Science Society of America.

2. Anonymous, 1993. FDA Regulatory Guidance for Toxins and Contaminants. Center for Food Safety and Applied Nutrition, United States Food and Drug Administration, College Park, MD.

3. Bai, G. H., Chen, L. F., and Shaner, G. 2003. Breeding for resistance to Fusarium head blight of wheat in China. Pages 296-317 in: Fusarium Head Blight of Wheat and Barley. K. J. Leonard and W. R. Bushnell, eds. American Phytopathological Society, St. Paul, MN.

4. Bai, G., and Shaner, G. 1996. Variation in Fusarium graminearum and cultivar resistance to wheat scab. Plant Dis. 80:975-979.

5. Bai, G. H, and Shaner, G. 2004. Management and resistance in wheat and barley to Fusarium head blight. Annu. Rev. Phytopathol. 42:135-161.

6. Bai, G. H., Shaner, G., and Ohm, H. 2000. Inheritance of resistance to Fusarium graminearum in wheat. Theor. Appl. Genet. 100:1-8.

7. Beyer, M., Roeding, S., Ludewig, A., and Verreet. J. A. 2004. Germination and survival of Fusarium graminearum macroconidia as affected by environmental factors. J. Phytopathol. 152:92-97.

8. Bushnell, W. R., Hazen, E., and Pritsch, C. 2003. Histology and physiology of Fusarium head blight. Pages 44-83 in: Fusarium Head Blight of Wheat and Barley. K. J. Leonard and W. R. Bushnell, eds. American Phytopathological Society, St. Paul, MN.

9. Chandler, E. A., Simpson, D. R., Thomsett, M. A., and Nicholson, P. 2003. Development of PCR assays to Tri7 and Tri13 trichothecene biosynthetic genes, and characterization of chemotypes of Fusarium graminearum, Fusarium culmorum and Fusarium cerealis. Physiol. Mol. Plant Pathol. 62:355-367.
10. Correll, J. C., Puhalla, J. E., and Schneider, R. W. 1986. Identification of Fusarium oxysporum $\mathrm{f}$. sp. apii on the basis of colony size, virulence, and vegetative compatibility. Phytopathology 76:396-400.

11. Cumagun, C. J. R., Bowden, R. L., Jurgenson, J. E., Leslie, J. F., and Miedaner, T. 2004. Genetic mapping of pathogenicity and aggressiveness of Gibberella zeae (Fusarium graminearum) toward wheat. Phytopathology 94:520-526.

12. Desjardins, A. E. 2006. Fusarium Mycotoxins: Chemistry, Genetics, and Biology. American Phytopathological Society, St. Paul, MN.

13. Desjardins, A. E., Proctor, R. H., Bai, G., McCormick, S. P., Shaner, G., Buechley, G., and Hohn, T. M. 1996. Reduced virulence of trichothecenenonproducing mutants of Gibberella zeae in wheat field tests. Mol. PlantMicrobe Interact. 9:775-781.

14. Dill-Macky, R. 2003. Inoculation methods and evaluation of Fusarium head blight resistance in wheat. Page 190 in: Fusarium Head Blight of Wheat and Barley. K. J. Leonard and W. R. Bushnell, eds. American Phytopathological Society, St. Paul, MN.

15. Dubin, H. J., Gilchrist, L., Reeves, J., and McNab, A., eds. 1997. Fusarium Head Scab: Global Status and Prospects. CIMMYT, Mexico, DF, Mexico.

16. Engle, J. S., Madden, L. V., and Lipps, P. E. 2003. Evaluation of inoculation methods to determine resistance reactions of wheat to Fusarium graminea rum. Plant Dis. 87:1530-1535.

17. Frohberg, R. C., Stack, R. W., Olson, T., Miller, J. D., and Mergoum, M. 2006. Registration of 'Alsen' wheat. Crop Sci. 46:2311-2312.

18. Gale, L. R., Harrison, S. A., Ward, T. J., O’Donnell, K., Milus, E. A., Gale, S. W., and Kistler, H. C. Nivalenol type populations of Fusarium graminearum and F. asiaticum are prevalent on wheat in Southern Louisiana. Phytopathology. In press.

19. Gale, L. R., Ward, T. J., Balmas, V., and Kistler, H. C. 2007. Population subdivision of Fusarium graminearum sensu stricto in the Upper Midwestern United States. Phytopathology 97:1434-1439.

20. Goswami, R. S., and Kistler, H. C. 2004. Heading for disaster: Fusarium graminearum on cereal crops. Mol. Plant Pathol. 5:515-525.

21. Horevaj, P., and Milus E. A. 2008. Resistance in winter wheat lines to initial infection and subsequent spread of deoxynivalenol and nivalenol chemotypes of Fusarium graminearum. Cereal Res. Commun. 36SB:499-502.

22. Horevaj, P., Milus, E., Gale, L., R., and Kistler, C. 2007. Resistance in soft red winter wheat lines to deoxynivalenol and nivalenol chemotypes of Fusarium graminearum. (Abstr.) Phytopathology 97:S48

23. Ichinoe, M., Kurata, H, Y. Sugiura, Y., and Ueno, Y. 1983. Chemotaxonomy of Gibberella zeae with special reference to production of trichothecenes and zearalenone. Appl. Environ. Microbiol. 46:1364-1369.

24. Kang, Z., Buchenauer, H., Huang, L., Han, Q., and Zhang, H. 2008. Cytological and immunocytochemical studies on responses of wheat spikes of the resistant Chinese cv. Sumai 3 and the susceptible cv. Xiaoyan 22 to infection by Fusarium graminearum. Eur. J. Plant. Pathol. 120:383-396

25. Lee, T., Han, Y. K., Kim, K. H., Yun, S. H., and Lee, Y. W., 2002. Tri3 and Tri7 determine deoxynivalenol- and nivalenol-producing chemotypes of Gibberella zeae. Appl. Environ. Microbiol. 68:2148-2154.

26. Mergoum, M., Frohberg, R. C., Stack, R. W., Rasmussen, J. W., and Friesen, T. L. 2008. Registration of 'Faller' spring wheat. J. Plant Regul. 2:224-229.

27. Mesterházy, Á. 1995. Types and components of resistance to Fusarium head blight of wheat. Plant Breed. 114:377-386

28. Miedaner, T., and Reinbrecht, C. 2001. Trichothecene content of rye and wheat genotypes inoculated with a deoxynivalenol- and a nivalenolproducing isolate of Fusarium culmorum. J. Phytopathol. 149:245-251.

29. Miller, J. D., Young, J. C., and Arnison, P. G. 1986. Degradation of deoxynivalenol by suspension cultures of the Fusarium head blight resistant wheat cultivar Frontana. Can. J. Plant Pathol. 8:147-150.

30. Minervini, F., Fornelli, F., and Flynn, K. M. 2004. Toxicity and apoptosis induced by the mycotoxins nivalenol, deoxynivalenol and fumonisin B-1 in a human erythroleukemia cell line. Toxicol. In Vitro 18:21-28.

31. Parry, D. W., Jenkinson P., and McLeod L. 1995. Fusarium ear blight (scab) in small grain cereals-a review. Plant Pathol. 44:207-238.

32. Patton-Özkurt, J., Navarro, R., and Cowger, C. FHB Type I Resistance in Wheat. Greenhouse Screening Protocol. http://scabusa.org/pdfs/ptt/cowger type1-screening_protocol.pdf.

33. Proctor, R. H., Hohn, T. M., and McCormick, S. P. 1997. Restoration of wild-type virulence to TRI5 disruption mutants of Gibberella zeae via gene reversion and mutant complementation. Microbiology 143:2583-2591.

34. Rudd, J. C., Horsley, R. D., McKendry, A. L., and Elias, E. M. 2001. Host plant resistance genes for Fusarium head blight: sources, mechanism, and utility in conventional breeding systems. Crop. Sci. 41:620-627.

35. Schroeder, H. W., and Christensen, J. J. 1963. Factors affecting resistance of wheat to scab caused by Gibberella zeae. Phytopathology 53:831-838.

36. Scott, P. M. 1997. Multi-year monitoring of Canadian grains and grainbased food for trichothecenes and zearalenone. Food Addit. Contam. 14:333-339.

37. Shimada, T., and Otani, M. 1990. Effects of Fusarium mycotoxins on the growth of shoots and roots at germination in some Japanese wheat cultivars Cereal Res. Commun. 18:229-232.

38. Stack, R. W. 2003. History of Fusarium head blight with emphasis on North 
America. Pages 1-35 in: Fusarium Head Blight of Wheat and Barley. K. J. Leonard and W. R. Bushnell, eds. American Phytopathological Society, St. Paul, MN.

39. Starkey, D. E., Ward, T. J., Aoki, T., Gale, L. R., Kistler, H. C., Geiser, D. M., Suga, H., Tóth, J., Varga, J., and O’Donnell, K. 2007. Global molecular surveillance reveals novel Fusarium head blight species and trichothecene toxin diversity. Fungal Genet. Biol. 44:1191-1204.

40. Ueno, Y., and Ishii, K. 1985. Chemical and biological properties of tricho- thecenes from Fusarium sporotrichioides. Pages 307-316 in: Trichothecenes and Other Mycotoxins. J. Lacey, ed. J. Willey. \& Sons, Chichester, England.

41. Ward, T. J., Clear, R., Rooney, A., O’Donnell, K., Gaba, D., Patrick, S., Starkey, D., and Geiser, D. M. 2008. An adaptive evolutionary shift in Fusarium head blight pathogen populations is driving the rapid spread of more toxigenic Fusarium graminearum in North America. Fungal Genet. Biol. 45:473-484. 